\title{
The Effects on Reading Comprehension of Lexical Collocation Instruction, Subject Matter Knowledge, and Cultural Schema
}

\author{
Mansoor Ganji \\ English Department, Chabahar Maritime University, Chabahar, Iran \\ Email: ganji@cmu.ac.ir
}

\begin{abstract}
This study investigated the effects of lexical collocation, topic and cultural familiarity on Iranian EFL learners' reading comprehension. There were thirty-eight English Translation students in Chabahar Maritime University participating in the present study, 15 freshmen and 23 sophomores. They were chosen from among 45 students based on their scores in the reading comprehension tests. In the treatment period, all the students received three different types of instruction in three consecutive weeks, and took a reading comprehension test after each type of instruction. . In the first week, they received a text that was culturally familiar to them; it was about the origin and development of banks and corporations in Iran. In the second week, they were taught the difficult lexical collocations of the reading text along with their Farsi equivalents before taking the test. And finally in the third week, the students read a reading passage which had the same topic as the reading test before; it was about the communication and behavior of ants. All the students were requested to complete a reading comprehension test, adopted from the paper-based TOEFL tests, after each type of instruction. According to the results demonstrated by the statistical program, a significant difference was found in reading comprehension among the participants based on the type of instruction they received. The highest mean belonged to the third week, when the students read a passage with the same topic before the test as the treatment, followed by the collocation instruction. However, there was no significant difference between boys and girls, and freshmen and sophomores as a result of different types of instruction.
\end{abstract}

Index Terms — reading comprehension, lexical collocation, topic familiarity, nativized text

\section{INTRODUCTION}

The role of vocabulary has been underestimated in the ESL/EFL education. Influenced by the Communicative Approach, teachers have ignored or even omitted vocabulary instruction in some EFL/ESL classes. Some researchers such as Brown (1974) cautioned our ESL/EFL field about the danger of ignoring vocabulary instruction, but it was not until the 1990s that scholars recognized the importance of vocabulary in the education of English as a second or foreign language, and devoted themselves to the improvement of vocabulary instruction.

Farghal and Obiedat $(1995)$ and Lewis $(1993,1997)$ specifically pointed out that the knowledge of collocations is of great importance and recognized this as prerequisite and indispensable in knowing a word. Lewis (1993, p. VI) argued that "language consists of grammaticalized lexis, not lexicalized grammar". In his view, learning collocations, the key component of grammaticalized lexis, is equal to language learning. Besides, many scholars believe that knowing a word includes knowing its collocations (Lewis, 2000; Nation, 1990, 2001).

Knowledge of collocations affects the production proficiency (Nattinger, 1980; Smadja, 1989), and the comprehension of input (Brown, 1974; Kelly, 1991). Jack Richards (1983) further pointed out that "where segmentation is difficult, comprehension is also difficult" (p. 220). In other words, a language learner may encounter difficulty in performing inference or comprehension if he is unable to segment the discourse into appropriate chunks (Berne, 2004). Besides these theoretical viewpoints about the importance and role of collocation knowledge in language learning, there are some experimental studies conducted to investigate the possible effect of collocation instruction on language skills, out of which just the most pertinent ones are included here.

Al-Zahrani (1998) came to the conclusion that there was a strong relation between the participants' knowledge of collocations and their overall language proficiency as assessed by TOEFL. Lien's (2003) research addressed the effects of lexical collocations instruction, single-item vocabulary instruction, and no instruction in relation to reading comprehension. The overall data analysis revealed that EFL learners who possessed better knowledge of collocations may be equipped with better abilities to comprehend reading texts. Such knowledge may serve as a marker of the academic levels of proficiency. What is more, collocation instruction indeed had some beneficial effects on the participants' reading comprehension in comparison with both single-item vocabulary instruction and no instruction.

Furthermore, reading is not a passive activity depending on the mere vocabulary or collocational knowledge of the learner. The reading is a very complex process which is influenced by many different factors. It is an active and interactive process and naturally presumes that readers have or should have some background knowledge about the 
topic of the text. Anderson (1999), for example, explained reading as follows: Reading is an active, fluent process which involves the reader and the reading material in building meaning. Meaning does not reside on the printed page. ... Synergy occurs in reading, which combines the words on the printed page with the reader's background knowledge and experiences. (p. 1)

Reading needs various mental operations to be performed simultaneously. When students read, they have to proceed from processing the text in smaller units of language to larger conceptual units (Perfetti, 1985). In fact, readers tend to deal with both micro-level text-driven features, such as pattern recognition, and lexical access, and macro-level readerdriven features, such as activation of prior knowledge and monitoring comprehension (Brantmeier, 2004). Each of these processes demands memory space, and thus may sometimes overload the working memory, which has a limited capacity (Pulido, 2003).

It has often been argued, however, that the cognitive load can be lessened by activating the necessary background knowledge of the readers (Pulido, 2004). When readers have relevant background knowledge about the topic, they can devote more attention for textual analysis and interpretation. As a result, existing background knowledge may contribute to the functioning of what are described as automatic processes by McLaughlin (1987). Schema theory discusses the role and importance of background knowledge in the reading process (Carrell \& Eisterhold, 1983). It deals with "preexisting knowledge structures stored in the mind" (Nassaji, 2002, p. 444) and its interaction with the text (Alptekin, 2006, Ketchum, 2006). It is mostly categorized as three types: formal, content, and cultural schemata.

Formal schema is the knowledge of language and linguistic conventions, the organization of the text, and the main features of a particular genre of writing. Content schema or the knowledge of the content is usually divided into two different types: background knowledge and subject matter knowledge. The former refers to the knowledge that may or may not be relevant to the content of a particular text, and the latter is directly related to the text content and topic (Alderson, 2000). And finally, Cultural schema or abstract schema is defined as a culture-specific extension of content schema because it refers to the role of cultural membership that is needed to fully comprehend the meaning intended by the writer. It is abstract in nature and involves cultural familiarity and helps readers to reconstruct the story line through referring to more personally and culturally relevant scripts (Nassaji, 2002).

There are different and sometimes opposing views regarding the effect of background knowledge and cultural schema on the reading proficiency. William's study (1983) showed that while high interest material enhanced comprehension, low interest material did not depress comprehension when compared to neutral interest material. Lipson (1984) suggested that partial knowledge can interfere with comprehension if it conflicts with the information in the text. Gordon (1987) also concluded that inaccurate or incomplete knowledge that is in conflict with the information presented in the text interferes with reading comprehension. Baldwin et al. (1985) found that prior knowledge and topic interest have an additive effect on reading comprehension. Several researchers have reported positive effects of cultural familiarity on reading comprehension (Alptekin, 2006) and vocabulary learning (Pulido, 2004). Alptekin (2006) found that when cultural elements of a short story are nativized to make the text culturally familiar, students can make better inferences than when they read the original story. Alptekin's findings give credence to Oller's (1995) assertion that changing certain words in authentic texts with more familiar ones helps readers to achieve better comprehension.

The last point which will be discussed in this study is the difference between male and females in the reading comprehension. In a study on the relationships between readers' sex, enjoyment, interest and L2 reading comprehension, Brantmeier (2003) indicated that reading performance, as measured by recall comprehension, was significantly influenced by passage content and readers' gender, whereas enjoyment and interest did not have any sizeable effect on the students' performances. Bügel and Buunk (1996) examined the impact of passage topic on gender differences in EFL reading comprehension using 2,980 high school students in the Netherlands. They selected a total of 11 different English reading passages including five texts with a 'male' topic and six texts with a 'female' topic. Males gained significantly better scores on the multiple choice comprehension items for texts about laser thermometers, volcanoes, cars, and football players. Females got significantly higher scores on the comprehension tests for essays such as midwives, a sad story, and a housewife's dilemma. They included a gender-neutral passage in their study, and they found that males performed significantly better than females on the gender-neutral text.

\section{A. Purpose of the Study}

It is a fact that reading comprehension tests are always basic components of all of the standardized exams, such as IELTS or TOEFL. Nevertheless, mastering reading skill has always been a challenge for EFL learners; and Iranian university students are not exceptions to this rule. In Iran, a few researchers have carried out studies on collocation proficiency. Although many collocation studies in Iran investigated the types of collocational errors students make while writing essays, few have studied the effect of collocations on language proficiency. As mentioned in the introduction section, knowledge of collocations was found to help learners in the reading comprehension. On the other hand, the subject matter knowledge and cultural schema are also shown to affect the reading comprehension positively. Thus, the present study aims to describe and examine the effect of direct instruction of lexical collocations on reading comprehension, and compare its effect with the effect of topic familiarity (similar topic and nativized text). To this end, the experiment carried out in this study aims at answering the following research questions.

(1) Are there significant differences in Iranian EFL learners' reading comprehension as a result of teaching lexical collocations, teaching a similar topic, and nativizing the reading text? 
(2) Which method of instruction helps the learners most in the reading comprehension: lexical collocation instruction, teaching a similar topic, or nativizing the reading text?

(3) Are there significant differences in Iranian EFL learners' reading comprehension as a result of teaching lexical collocations, teaching a similar topic, and nativizing the reading text between freshmen and sophomores?

(4) Are there significant differences in Iranian EFL learners' reading comprehension as a result of teaching lexical collocations, teaching a similar topic, and nativizing the reading text between boys and girls?

\section{B. Significance of the Study}

Although the knowledge of lexical collocations is so important in learning a foreign or second language, no study has been conducted to report the effects of teaching collocations on reading comprehension in Iran, thus this study contributes directly to our understanding of the nature of collocations in general, and its effect on reading comprehension in particular. The results of the study will shed light in this regard, and will show if collocations are a worth-teaching aspect of language. On the other hand, it is generally believed that familiarity with the topics of reading or writing in IELTS and TOEFL can help students have a better performance in the exam; as a result, most of the Iranian English Language Institutes and English teachers who are preparing students for these exams mostly focus their teaching on similar topics and texts in the hope that the students will get better marks in the exam. The findings can be useful for EFL learners who have difficulty with reading sections of TOEFL or IELTS, and also for English teachers to decide whether teaching the similar topics or the essential vocabulary or collocations of the texts can help students more. It can also guide material designers to consider collocations while preparing EFL/ESL books.

\section{MEthodology}

\section{A. Research Design}

This study investigates the effect of lexical collocations instruction and topic familiarity on the Iranian EFL learners' reading skill. It aims to compare the effects of lexical collocation instruction, and topic familiarity (similar topic and nativized text) on the reading skill of Iranian students, and to see which treatment yields better results. The research design of the present study is quasi-experimental, since intact classes are used, not randomly chosen students. It obtains volunteer participants from Chabahar Maritime University English students. The design of the study is similar to the one conducted by Lien (2003), but with some modification. That study investigated the effect of lexical collocation instruction, single-item vocabulary instruction, and no instruction on the reading comprehension of the students, but this study replaced no instruction with familiar topic instruction, and single-item vocabulary instruction with culturally familiar text.

\section{B. Setting and Participants of the Study}

This study was conducted at the English department of Chabahar Maritime University. It obtained 38 volunteers from two different academic levels (fresh and sophomore). Two intact classes, one fresh and one sophomore, volunteered to participate in the study. They were between 18 and 23 years old. At that time, fresh students had passed grammar, reading and conversation courses, while sophomores had passed some translation courses in addition to these courses. However, none of the groups had passed any course related to collocation at that time. In these two classes, there were thirty-eight undergraduate students (15 fresh and 23 sophomores) in total. Among these participants, 18 of them were male and the other 20 students were female. They were 45 English majors at the beginning of the study. However, after taking the TOEFL reading test and analyzing the scores, 7 of the students whose marks were far below the mean were excluded and those students who were almost at the same level of reading proficiency were chosen as the participants of the study.

\section{Instrumentation}

The instruments exploited in the present study were three TOEFL reading tests. Each test consisted of one reading passage, followed by 10 multiple choice questions, which is almost a norm in TOEFL reading. The reading used in the first week was about the origin and development of banks and corporations in Iran. In the second week, a text entitled: Extinction of animals was used as the test. The reading used in the third week was about the way ants communicate with each other. They were all taken from the paper-and-pencil practice tests of TOEFL, published by Educational Testing Service. The second instrument was the statistical program, Statistical Package for the Social Sciences (SPSS) version 17.

\section{Treatments}

Three types of instruction -producing a nativized text, teaching lexical collocations, and teaching a similar topic, were included as the treatments in this experiment. In the first week, the students had no instruction in the class before the test, but the reading test was about a topic that was quite familiar to them culturally, it was about the origin and development of banks and corporations in Iran. Alptekin's (2006) believed that in order to make a text culturally familiar for the students, we do not need to use two texts of similar difficulty, but we cam make use of the same text only by changing some cultural elements, such as the names of people and places, and by adapting them to the students' 
own cultural context. This, according to Alptekin, reduces the possible bias posed by varying levels of conceptual density and complexity in different texts. So, the original TOEFL reading passage which was about the origin and development of banks in USA was taken as the source, and it was nativized by replacing all the names of people, corporations, places, and dates. So, the students took a reading passage that was culturally familiar to them.

In the second week, the students received collocation instruction for 30 minutes in their own classroom respectively. In this type of instruction, difficult lexical collocations of the passage were presented to the students, and their Farsi equivalents were given to them on a piece of paper. The students got together in groups and made sentences with them. At the end of the class, the students took the reading test, the collocations of which were presented to them before.

In the third week, all the participants were given a passage that was about the same topic as the reading test. The reading was about the behavior and communication of ants. The students read the text aloud in the class, talked about it and asked any questions regarding the meaning and structure of the text. After that, they took the reading test and answered the following 10 multiple-choice questions.

\section{E. Data Collection Procedure}

The study was conducted in three consecutive weeks from the second week to the fourth week of the semester in Chabahar Maritime University. Right after each type of instruction, participants had to take a paper-and-pencil reading comprehension test. The students were given one reading passage of around 230 words, and answered 10 multiple choice questions based on the information presented in the passage. So the scores of the students ranged from 1 to 10 in the reading test, because the questions were multiple-choice and for each question there was only one correct answer. After the calculation of the scores for each comprehension test, the scores of the participants were recorded for the data analysis process.

\section{F. Data Analysis}

To compare the effectiveness of the three types of instruction, data collected from the comprehension tests were used for statistical analysis. Firstly, the mean scores of all the students on the experimental tests under three different types of instruction were examined. This was done to find out which treatment had the best results on the reading comprehension of Iranian EFL learners. Secondly, the mean scores of the experimental tests under three different types of instruction between two different academic levels were compared. This analysis was carried out to see if the effect of different treatments differs between the academic levels. And finally, to find out if there were significant differences between boys and girls as a result of different types of treatment, the mean scores of boys and girls under different treatments were compared. Repeated-measures Analysis of Variance was employed in all these steps, because there is no control group in this study, and students themselves act as their control group. If any significant differences were found in the results, post-hoc comparisons would be utilized to explore where exactly the differences occurred.

\section{RESUlTS AND DiSCUSSION}

In order to get a general picture of the students' performances in the reading comprehension test after different types of instruction, the descriptive statistics of the three reading tests are displayed in Table 1. As it can be seen, the students had their best performance in the last week of the treatment, their mean is 7.50. Thus, reading a passage with the same topic, or increasing the subject matter knowledge of the students helped them more than any other treatment. The second most successful technique used in this study turned out to be collocation instruction. Therefore, knowing the difficult collocations or chunks of words chosen from the reading test can be a great helping hand for the students, although not comparable with having enough knowledge about the subject.

TABLE 1:

DESCRIPTIVE STATISTICS OF READING TESTS AFTER THREE TYPES OF INSTRUCTION

\begin{tabular}{|l|l|l|l|}
\hline Instruction Type & Mean & Std. Deviation & $\mathrm{N}$ \\
\hline Reading Comprehension Test(Nativized Text) & 6.36 & 1.58 & 38 \\
\hline Reading Comprehension Test(Collocation Instruction) & 7.18 & 1.48 & 38 \\
\hline Reading Comprehension Test(Similar Topic) & 7.50 & 1.26 & 38 \\
\hline
\end{tabular}

However, we cannot decide about the significance difference between the three types of treatments by just looking at the mean scores. To find out if there were any differences in students' reading comprehension as a result of three different types of instruction, a Repeated-Measures ANOVA was employed to investigate the observable variation in participants' performances, since the same students took the reading tests three times in this experiment. The results of the Repeated-Measures ANOVA are shown in Table 2. Based on these results, it can be concluded that there was a significant difference between the mean scores of the students in the three reading tests as a result of different types of instruction. Therefore, it is safe to say that the different types of instruction used in this study influence the performances of the students differently. But, this table cannot show us where the differences are significant and where not. 
TABLE 2:

REPEATED-MEASURES ONE-WAY ANOVA RESULTS FOR THE THREE TYPES OF INSTRUCTION

\begin{tabular}{|ll|l|l|l|l|l|}
\hline Source & Type III Sum of Squares & df & Mean Square & F & Sig. \\
\hline Instruction Type & Sphericity Assumed & 25.91 & 2 & 12.95 & 9.841 & $.000 \square$ \\
& Greenhouse-Geisser & 25.91 & 1.73 & 14.92 & 9.841 & $.000 \square$ \\
& Huynh-Feldt & 25.91 & 1.81 & 14.28 & 9.841 & $.000 \square$ \\
& Lower-bound & 25.91 & 1.00 & 25.91 & 9.841 & $.003 \square$ \\
\hline
\end{tabular}

To compare the different instruction types with each other and to see which instruction type is the best, a post-hoc comparison test should be run on the data. According to the results displayed in Table 3 , the mean difference of 0.816 $(p<.05)$ indicates that there is a statistically significant difference between the performances of students in the first week and the second week. It shows that collocation instruction is a more successful technique for preparing students for the reading test than using nativized texts, because it helps them understand the text better and, hence be able to answer more comprehension questions. This finding is consistent with Lien's (2003) and Hsu, T. J. (2010) studies which suggested that collocation instruction is more useful than single-item vocabulary instruction in preparing the students for the reading comprehension tests and vocabulary recall tests. Brown (1974) and Kelly (1991) also believed that knowledge of collocations helps the students a lot in language comprehension skills of reading and listening. However, these findings contrast with previous researches who suggested that when cultural elements of a short story are nativized to make the text culturally more familiar, students can make better inferences than when they read the original but culturally-remote story (Oller, 1995 \& Alptekin, 2006). There are two reasons which might justify this opposition of ideas. Firstly, these scientists compared the comprehension of a nativized text with its original version, and it is quite natural that a culturally familiar text is easier to understand for students than its original version. In other words, nativizing the text might seem a good technique, but not in comparison with collocation instruction. When students know the difficult collocations of a text, they know the building blocks of that text, so reading comprehension becomes much easier to understand. The second reason is that nativizing the text might be a good help for non-English majors who do not have that much information about, or contact with the English culture. Since this study participants are all English majors, and they have a lot of contact with foreign culture and literature, nativizing the texts does not influence their comprehension very much.

Furthermore, the mean difference of $1.132(p<.05)$ also suggests that there is a statistically significant difference between the performances of students in the first week and the third weeks. Thus, activating the background knowledge of the students; or more precisely, the subject matter knowledge of the students seems to be of great help to the students in taking the reading test. These results confirmed what has been widely acknowledged as the positive effect of background knowledge on the reading comprehension (Alderson, 2000; Alptekin, 2006; Ketchum, 2006; Oller, 1995; Pulido, 2003). It also gives credence to the claim that the cognitive load involved in reading comprehension can be lessened by activation of the background knowledge that readers bring to the text (Nassaji, 2002, and Pulido, 2004). When readers bring relevant background knowledge to the reading process, they can allocate more attentional space for textual analysis and interpretation. Peretz, A. S. and Shoham, M. (1990) also reached the conclusion that students of Humanities and Social Sciences performed much better on the reading tests including passages about their own fields than texts related to Science and Technology fields. Therefore, students of different fields are more relaxed with texts about their own major than passages taken from other fields' books.

The only difference which was not significant in this study was the difference between collocation instruction and same topic teaching. It seems that while knowing the lexical collocations of the text helps students understand the sentences better, having knowledge of the subject matter puts the students in a better mental position, and creates a more relaxed atmosphere for them. It cannot be decided whether lexical collocation instruction or subject matter knowledge is the best method of preparing students for the reading exam, because the difference between them is not significant. Nonetheless, the scores of the students are slightly higher in the third week than the second week.

TABLE 3:

POST-HOC SCHEFFE" S TEST RESULTS FOR THREE TYPES OF INSTRUCTION

\begin{tabular}{|c|l|l|l|l|l|}
\hline & & & \multicolumn{2}{|l|}{$95 \%$ Confidence Interval } \\
\cline { 5 - 6 } \cline { 5 - 6 } Pairwise Comparisons & Mean Difference & Std. Error & Sig. & Lower Bound & Upper Bound \\
\hline Nativized $\quad$ Collocation & $-.816^{*}$ & .206 & .001 & -1.333 & -.299 \\
& $-1.132^{*}$ & .293 & .001 & -1.865 & -.398 \\
\hline Same Topic & $.816^{*}$ & .206 & .001 & .299 & 1.333 \\
Collocation Nativized & -.316 & .283 & .813 & -1.024 & .393 \\
Same Topic & $1.132^{*}$ & .293 & .001 & .398 & 1.865 \\
\hline Same Topic Nativized & .316 & .283 & .813 & -.393 & 1.024 \\
Collocation & &
\end{tabular}

*. The mean difference is significant at the .05 level. 
Now that research questions 1 and 2 are answered, it is time to go to question 3 which is about the difference between freshmen and sophomores performances in reading comprehension due to different types of instruction. Again, it is necessary to use repeated-measures ANOVA to find out if freshmen and sophomores perform differently as a result of different treatments. Based on the results of Table 4, it can be concluded that there was no significant difference between the mean scores of the two academic levels on the reading comprehension tests as a result of different types of instruction. That is to say, the two groups were not influenced differently by the treatment methods. It is not surprising since they were almost at the same level of reading proficiency at the beginning of the study, as measured by the TOEFL reading test. Furthermore, this result endorses the conclusions reached by Lien (2003) and Hsu, T. J. (2010) working on the effect of direct collocation instruction on reading and vocabulary recall tests. They found no significant difference between the performances of different academic levels on the reading comprehension test and vocabulary recall tests as a result of collocation instruction, single-item vocabulary instruction, and no instruction.

TABLE 4:

REPEATED-MEASURES ONE-WAY ANOVA RESULTS FOR THE THREE TYPES OF INSTRUCTION BETWEEN ACADEMIC LEVELS

\begin{tabular}{|ll|l|l|l|l|}
\hline Source & & Type III Sum of Squares & df & Mean Square & F \\
\hline Instruction * Level & Sphericity Assumed & .763 & 2 & .381 & Sig. \\
& Greenhouse-Geisser & .763 & 1.796 & .425 & .307 \\
& Huynh-Feldt & .763 & 1.996 & .382 & .307 \\
& Lower-bound & .763 & 1.000 & .763 & .307 \\
\hline
\end{tabular}

As regards the fourth research question, seeking the possible difference between the performances of boys and girls under different types of instruction, repeated-measures ANOVA was employed. As indicated in Table 5, there is no significant difference between boys and girls in the reading comprehension tests as a result of different types of instruction. No other study has investigated the possible difference between the performances of boys and girls as a result of different types of instruction before. However, there are so many studies investigating the differences between sexes in language proficiency tests or the interaction of sex and background knowledge on reading comprehension, all with opposing results. Hyde and Linn (1988) argued that the score gap between males and females on the verbal section of the Scholastic Aptitude Test (SAT) was largely due to the content of the reading materials in the test. According to them, the reading passages on verbal section of the SAT have covered more technical topics (e.g., physics or chemistry), thus disadvantaging females in the performance of the test. Dolittle and Welch (1989) also found notable gender differences for items associated with specific passages, reporting that females scored higher than males with humanities-oriented reading passages, but lower than male with science-oriented passages.

TABLE 5:

REPEATED-MEASURES ONE-WAY ANOVA RESULTS FOR THE THREE TYPES OF INSTRUCTION BETWEEN BOYS AND GIRLS

\begin{tabular}{|ll|l|l|l|l|l|}
\hline Source & & Type III Sum of Squares & df & Mean Square & F & Sig. \\
\hline Instruction * Gender & Sphericity Assumed & 1.973 & 2 & .986 & .793 & .457 \\
& Greenhouse-Geisser & 1.973 & 1.796 & 1.098 & .793 \\
& Huynh-Feldt & 1.973 & 1.945 & .989 & .793 \\
& Lower-bound & 1.973 & .456 & .793 & .379 \\
\hline
\end{tabular}

\section{CONCLUSION AND IMPLICATION}

This study came to the conclusion that teaching lexical collocation has a positive effect on the reading ability of the students, so it is recommended that teachers and material designers adjust their curriculum to include the teaching of lexical collocations into their current practices. The new words should not be presented as single-item vocabularies. It is better to present them as collocation, at least with one or two more items. Teachers ought to familiarize their students with the concept of collocation, teach different types of collocation to them, and raise their awareness of such combinations through different exercises such as highlighting. This may imply that explicit collocation instruction is necessary to improve EFL/ESL learners' reading comprehension. This result seems to confirm previous scholars' propositions concerning the following aspects. First, vocabulary should be taught collocationally rather than individually. Knowing what other words a word will collocate with, in fact, has already been considered as an important aspect of knowing a word (Nation, 1990). Farghal and Obiedat (1995), moreover, explicitly emphasized that vocabulary should always be taught together with certain words that it can collocate with instead of single item.

The study found a significant difference between the performances of the students as a result of nativizing the text and increasing the students' knowledge of the topic in the first and third weeks. Thus, the English language Institutes and teachers are right in their decision in working on the topics which are usually covered in the reading sections. The subject matter knowledge seems to put students at ease in the reading tests, while encountering a quite new topic full of new words and technical expressions surely reduces the students' confidence in the exam, and affects their scores negatively. As discussed before, there was no significant difference between the students' performances on the reading 
tests after collocation instruction and same topic. Thus, both of them can be used in TOEFL and IELTS preparation courses, and are theoretically successful enough. Practically speaking, it seems almost impossible to prepare the students for all of the reading topics, because there are so many topics covered in the reading section, and they are so varied that it takes years to finish the topics. Furthermore, the option of nativizing the texts is not logical and more importantly quite impossible, we cannot have an Iranian version of TOEFL or IELTS, the best option is to familiarize the students with the core and basic vocabulary of the texts. It is right that students cannot be taught all the possible topics of the reading section, there are some certain academic words and expressions which are common among most texts.

To improve the learners' knowledge of collocations, teachers can start from their instruction. Teachers can adjust their curriculum to accommodate the teaching of collocations into their current practices. English learners should be made aware of their insufficient collocational knowledge, and the importance of collocational knowledge in language comprehension and production. They need to make an effort to build up their collocation size to improve their collocational knowledge. However, this daunting task cannot be accomplished by students alone; they need to be supported by teachers and material designers. Textbook designers should emphasize and highlight collocations in textbooks. Syllabus designers might benefit from the results of this study by bringing collocation into focus and arranging the collocations students need in a meaningful way and presenting them topically.

The study suffers from a number of limitations. Very few participants were involved in this study. More importantly, the fact that they were not randomly selected is another limitation. The small number and homogenous background of the subjects may make it difficult to generalize to all the college EFL learners. Future studies of the same kind are expected to recruit more participants and provide a more thorough understanding about the Iranian learners' knowledge of lexical collocations and its effect on other skills. Another limitation of this study is the scope of collocations. The research data was restricted to lexical collocations and did not include grammatical collocations. If both lexical and grammatical collocations are examined, a deeper understanding of the students' use of collocations and its relation to their writing and speaking fluency may be provided. Last, but not the least important, limitation of the study was the length of the treatment. The treatments of this study did not last for a long time; it was, as a matter of fact, limited to 30 minute blocks in each session. Due to the consideration of the original syllabus for the course, it was impossible to implement the research for a long time.

\section{REFERENCES}

[1] Alderson, J. C. (2000). Assessing reading. Cambridge, England: Cambridge University Press.

[2] Alptekin, C. (2006). Cultural familiarity in inferential and literal comprehension in L2 reading. System 34.4, 494-508. 261-275.

[3] Al-Zahrani, M. S. (1998). Knowledge of English lexical collocations among male Saudi college students majoring in English at a Saudi University. Ph.D. dissertation, Indiana University of Pennsylvania.

[4] Anderson, N. J. (1999). Exploring second language reading. Boston, MA: Heinle \& Heinle.

[5] Baldwin, R.S., Peleg-Bruckner, Z. \& McClintock, A.H. (1985). Effects of topic interest and prior knowledge on reading comprehension. Reading Research Quarterly 20.4, 497-504.

[6] Berne, J. E. (2004). Listening comprehension strategies: A review of the literature. Foreign Language Annals 37.4, 521-533.

[7] Brantmeier, C. (2004). Building a comprehensive theory of adult foreign language reading: A variety of variables and research methods. The Southern Journal of Linguistics 27.1, 1-7.

[8] Brown, D. F. (1974). Advanced vocabulary teaching: The problem of collocation. RELC Journal 5.2, 1-11.

[9] Bügel, K., \& Buunk, B. P. (1996). Sex differences in foreign language text comprehension: The role of interests and prior knowledge. The Modern Language Journal 80.1, 15-31.

[10] Carrell, P. L., \& Eisterhold, J. C. (1983). Schema theory and ESL reading. TESOL Quarterly 17.4, 553-573.

[11] Doolittle, A., \& Welch, C. (1989). Gender differences in performance on a college level achievement test. Iowa City, IA.: American College Testing Programme.

[12] Farghal, M. \& Obiedat, H. (1995). Collocations: A neglected variable in EFL. IRAL 33.4, 315-331.

[13] Gordon, C. (1987). The effect of testing method on achievement in reading comprehension tests in English as a foreign language. M.A. thesis, Tel Aviv University.

[14] Hsu, T. J. (2010). The effects of collocation instruction on the reading comprehension and vocabulary learning of Taiwanese college English majors. Asian EFL Journal 12.1, 47-87.

[15] Hyde, J. S., \& Linn, M. C. (1988). Gender differences in verbal activity: A meta-analysis. Psychological Bulletin 104, 53-69.

[16] Kelly, P. (1991). Lexical ignorance: The main obstacle to listening comprehension with advanced foreign language learners. International Review of Applied Linguistics in Language Teaching 29.2, 135-149.

[17] Ketchum, E. M. (2006). The cultural baggage of second language reading: An approach to understanding the practices and perspectives of a nonnative product. Foreign Language Annals 39.1, 22-42.

[18] Lewis, M. (1993). The lexical approach: The state of ELT and a way forward. London: Language Teaching Publications.

[19] Lewis, M. (1997). Implementing the lexical approach: Putting theories into practice. London: Language Teaching Publications.

[20] Lewis, M. (2000). Teaching collocation: Further developments in the lexical approach. London: Language Teaching Publications.

[21] Lien, H.Y. (2003). The effects of collocation instruction on reading comprehension of Taiwanese college students. Ph.D. dissertation, Indiana University of Pennsylvania.

[22] Lipson, M.Y. (1984). Some unexpected issues in prior knowledge and comprehension. The Reading Teacher 37.8, $760-764$.

[23] McLaughlin, B. (1987). Theories of second language learning. London: Edward Arnold. 
[24] Nassaji, H. (2002). Schema theory and knowledge-based processes in second language reading comprehension: A need for alternative perspectives. Language Learning 52.2, 439-481.

[25] Nation, I. S. P. (1990). Teaching and learning vocabulary. New York: Heinle and Heinle.

[26] Nation, I. S. P. (2001). Learning vocabulary in another language. Cambridge: Cambridge University Press

[27] Nattinger, J.R. (1980). A lexical phrase grammar For ESL. TESOL Quarterly 14.3, 337-344.

[28] Oller, J. W. (1995). Adding abstract to formal and content schema: Results of recent work in Peircean semiotics. Applied Linguistics 16.3, 273-306.

[29] Perfetti, C. (1985). Reading ability. New York: Oxford University Press.

[30] Peretz, A. S., \& Shoham, M. (1990). Testing reading comprehension in LSP: Does topic familiarity affect assessed difficulty and actual performance? Reading in a Foreign Language 7.3, 447-445.

[31] Pulido, D. (2003). Modeling the role of second language proficiency and topic familiarity in second language incidental vocabulary acquisition through reading. Language Learning 53.2, 233-284.

[32] Pulido, D. (2004). The effects of cultural familiarity on incidental vocabulary acquisition through reading. The Reading Matrix 4.2, 20-53.

[33] Richards, J. C. (1983). Listening comprehension: Approach, design, procedure. TESOL Quarterly 17.2, $219-239$.

[34] Smadja, F. A. (1989). Lexical co-occurrence: The missing link. Literary and Linguistic Computing 4.3, 163-168.

[35] Williams, R. (1983). Teaching the recognition of cohesive ties in reading a foreign language. Reading in a Foreign Language $1.1,35-52$.

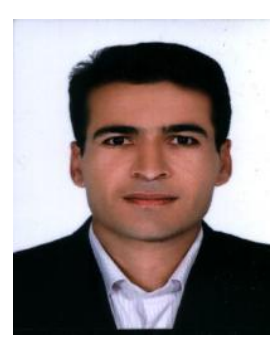

Mansoor Ganji is a lecturer of TEFL at the English Department of Chabahar Maritime University. He holds an M.A. in TEFL (Allameh Tabatabaii University, 2006), and a B.A. in Translation Studies (Chabahar Maritime University, 2002). He started his career of teaching at Chabahar Maritime University and International University of Chabahar in 2006 and currently teaches graduate courses in Writing, Translation, Interpretation, and Methodology.

His main areas of interest include written feedback, collocation learning, and IELTS proficiency test. He has published some articles on TEFL in Journals of Applied Linguistics, and presented papers in national and international conferences. Some of his recent publications include: "The best way to teach phrasal verbs: Translation, sentential contextualization or metaphorical conceptualization?" (Theory and Practice in Language Studies) and "Teacher-correction, peer-correction, and self-correction: Their impacts on Iranian students' IELTS writing performance” (THE JOURNAL OF ASIA TEFL). 